\title{
Comment to: Hernia research in developing countries: are we looking for needles in haystacks? Insights from the Danish model
}

\author{
L. N. Jorgensen ${ }^{1} \cdot$ H. Friis-Andersen ${ }^{2}$
}

Received: 15 May 2020 / Accepted: 26 May 2020 / Published online: 3 June 2020

๑) Springer-Verlag France SAS, part of Springer Nature 2020

\section{Dear Editor,}

Piltcher-da-Silva and coworkers should be acknowledged for their honest communication in describing the multiple challenges related to long-term follow-up in a developing country like Brazil [1]. Indeed, many of these obstacles are faced also by the clinicians in developed countries, and the recent Covid-19 pandemic may aggravate these conditions.

In Denmark, there has been ideal conditions for clinical health related data registries for decades owing to a national unique and personal identity number given to each citizen at birth. This identity number is centrally captured for all contacts to the health system (excluding contacts to the general practitioner) including both public and private hospitals [2, 3]. The current address of the patient is also electronically linked to this personal number. This allows for collection of follow-up data including diagnoses and type of operations in all institutions of Denmark until emigration or death of the patient. Registration of the personal identity number also provides the opportunity to merge data from other national registries such as databases for medical prescriptions, birth, occupancy, economical income, education etc. This has created a strong epidemiological tool for scientific research.

As touched upon by Piltcher-da-Silva et al. setting up late outpatient follow-up appointments is difficult and probably impossible in the long run due to the increasing burden of an accumulating number. The many publications from the Danish Hernia Database [4] rely on the most important longterm events such as diagnoses leading to hospital admission or re-operation. If more detailed information such as QOL

L. N. Jorgensen

LarsNJorgensen@hotmail.com

1 Department of Digestive Disease, Bispebjerg Hosptial, University of Copenhagen, 2400 Copenhagen, NV, Denmark

2 Department of Surgery, Regionshospitalet Horsens, University of Aarhus, 8700 Horsens, Denmark or chronic pain is required, questionnaires must be sent out to subgroups of patients selected from the registry.

This is not a free lunch, though. As pointed out by Köckerling, it is key that one obtains both the pre- and perioperative data from the patient to obtain full value of the future postoperative data [5]. As this online reporting immediately after surgery is required by all Danish surgeons performing hernia repair, we have kept the registration process simple to obtain a high level of participation. A typical registration thus takes less than two minutes. Although this is requested by Danish law and does not require informed consent from the patient, we "only" reach registration rates of approximately $90 \%$ of all inguinal hernia repairs and $80 \%$ of all ventral hernia repairs in Denmark. These high rates have been achieved following the principal ideas of the founder of the Danish Hernia Database, Henrik Kehlet, of keeping the data registration quick and regularly providing feed back of the results to the participating surgeons at national meetings.

Apart from dedicated surgeons, a successful data registry depends on the commitment of society to provide opportunity for the researcher to both identify and follow patients to capture the important hard outcome data years ahead.

\section{Compliance with ethical standards}

Conflict of interest Drs Lars N Jorgensen and Hans Friis-Andersen declare that they have no conflict of interest.

Ethical approval Approval from the institutional review board was not required for this study.

Human and animal rights This article does not contain any studies with human participants or animals performed by any of the authors.

Informed consent For this communication, informed consent is not required. 


\section{Reference}

1. Piltcher-da-Silva $\mathrm{R}$ et al (2020) Hernia research in developing countries - are we looking for needles in haystacks? Hernia. https ://doi.org/10.1007/s10029-020-02235-1

2. Friis-Andersen H, Bisgaard T (2016) The Danish Inguinal Hernia database. Clin Epidemiol 8:521-524. https://doi.org/10.2147/ CLEP.S99512

3. Helgstrand F, Jorgensen LN (2016) The Danish Ventral Hernia Database - a valuable tool for quality assessment and research. Clin Epidemiol 8:719-723. https://doi.org/10.2147/CLEP.S99501
4. https://www.herniedatabasen.dk/litteraturliste (2020) Danish Hernia Database publication list. Accessed 14 May 2020

5. Köckerling F (2020) Comment to: Hernia research in developing countries-are we looking for needles in haystacks? Follow-up is the Achilles heel of every registry. Hernia, (in press)

Publisher's Note Springer Nature remains neutral with regard to jurisdictional claims in published maps and institutional affiliations. 